\title{
Petit Mal Epilepsy
}

National Cancer Institute

\section{Source}

National Cancer Institute. Petit Mal Epilepsy. NCI Thesaurus. Code C3023.

Epilepsy characterized by very brief episodes of sudden cessation of activity, usually associated with eye blinking. There is no loss of the muscle tone. 